\title{
AURAL 2 : Robots and a Generative System in an Algorithmic Composition Process
}

\author{
Artemis Moroni ${ }^{1}$, Jônatas Manzolli ${ }^{2}$, Mariana Shellard ${ }^{2}$ \\ ${ }^{1}$ CTI Renato Archer, Robotics and Computer Vision Division, Rod. D. Pedro I, km 143,6, \\ 13069-901, Campinas, SP, Brazil \\ artemis.moroniecti.gov.br \\ ${ }^{2}$ Unicamp, Interdisciplinary Nucleus of Sound Studies, Rua da Reitoria, 165, \\ Cidade Universitária Zeferino Vaz, 13083-872, Campinas, SP, Brazil \\ jonatas@nics.unicamp.br \\ marianashellardegmail.com
}

\section{Extended Abstract}

An artificial vision system, mobile robots and a generative process were applied for sound production in $\mathrm{AURAL}_{2}$, a robotic art installation [1]. Generative systems have many similarities with systems found in various areas of science; they may provide order and disorder, as well as a varying degree of complexity, making behavioral prediction difficult. However, such systems still contain a definite relation between cause and effect. The artist (or creator) generally provides basic rules, and then defines a process, random or semi-random, to work on these elements. The results continue to happen within the limits domain of the rules, but also may be subjected to subtle changes or even surprises [2].

In the AURAL $L_{2}$, synthetic, game and everyday sound fragments are inserted into a database, the memory of the system. Each sound fragment is associated with a cell in a virtual grid, projected on a winding format platform ( $3 \mathrm{~m} \times 3 \mathrm{~m}$ wide, $0.3 \mathrm{~m}$ high), or stage (Figure 1). A hole inside the platform creates tracks that may be travelled on by only one robot or two robots. The robots have a border sensor, they stop when they detect the border. In the other regions of the platform, three or four robots can move around. This design cases conflicts among the robots when they try to escape from confined areas. The robots are tracked by a vision system which evaluates the position $(\mathrm{x}, \mathrm{y})$ of the robots on the stage; associates a cell in the matrix with that position and plays the sound fragment associated with it. The movement of the robots through the different regions of the stage triggers the sound of the associated cells, (re)creating soundscapes in the installation environment.

On a TV, the virtual grid is shown in several angles, as well as the cells activated by the robots (Figure 6). The visitors may interact with the system by talking, singing or screaming at a microphone, starting the intervention process: sound fragments are extracted from the interventions of the visitors and randomly inserted into the environment matrix; there is a possibility of the segments to be triggered and played again by the movement of the robots. A spectral analysis is applied on the fragment that caused the intervention, and two visual effects may be perceived by the visitors. 
When there is more energy in the upper partials of the sound fragment, the following actions take place: the color of the cell associated with that fragment is changed to red on the TV, otherwise to blue. A rotation is applied on the grid. Finally, the sound fragment is inserted into the sound data base, i. e., the memory of the system, superposing a previous one, enhancing a recycling acoustic process. Thus the AURAL $_{2}$ intervenes in the sound ecology, generating new aural trajectories with the everyday sounds.

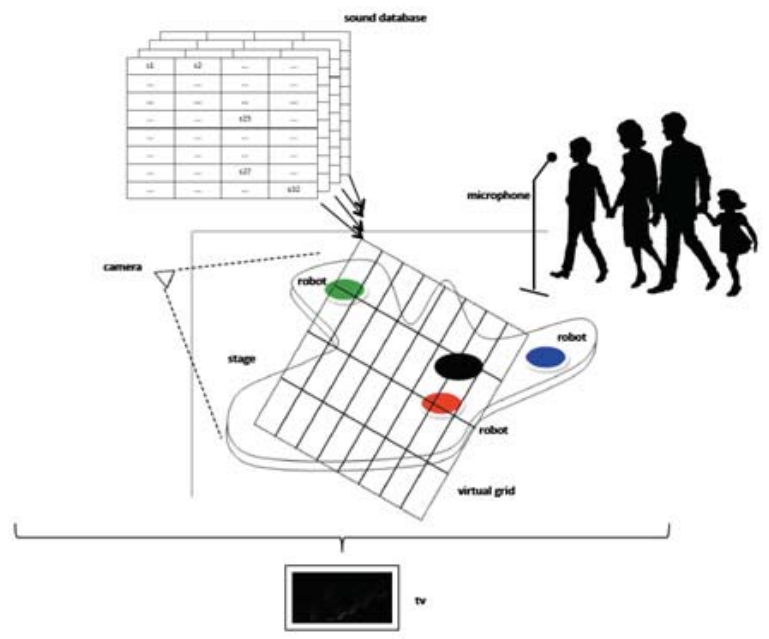

Fig. 1 The components of $\mathrm{AURAL}_{2}$ : sound database, camera, microphone, robots.

\section{Acknowledgements}

We thank the students Felipe Shida and Daniel Kantor. We thank the Scientific Initiation Program of the National Research Council (PIBIC/CNPq), the Center for Technology Information Renato Archer and the Interdisciplinary Nucleus for Sound Studies of the State University of Campinas (NICS/UNICAMP) for making this research possible. We thank the Serviço Social do Comércio (SESC) for its sponsorship and opportunity of presenting this work at SESC-Campinas gallery. This research work was part of the AURAL project, supported by the Foundation for the Research in São Paulo State (FAPESP) process 05/56186-9. Manzolli is supported by the Brazilian Agency CNPq. This work is licensed under the Creative Commons [CC-BY].

\section{References}

1. Moroni, A., Manzolli, J.: AURAL 2 . In: INSTANTE, Arte e Tecnologia no SESC Campinas, Serviço Social do Comércio, 2011.

2. Moroni, A., Manzolli, J.: Multimodal Robotic Artistic Installations for Sound Production. In: Anais do IV Seminário de Música, Ciência e Tecnologia, 2012, São Paulo. 